\title{
PENGEMBANGAN HYPERTEXT SAINS KEARIFAN LOKAL BALI BERBASIS DATABASE
}

\author{
Ida Bagus Nyoman Sudria ${ }^{1}$, Komang Setemen ${ }^{2}$ \\ 1Jurusan Pendidikan Kimia, Fakultas MIPA, Universitas Pendidikan Ganesha, \\ Singaraja, Indonesia \\ ${ }^{2} J u r u s a n$ Manajemen Informatika, Fakultas Teknik dan Kejuruan, \\ Universitas Pendidikan Ganesha, Singaraja, Indonesia
}

\begin{abstract}
Abstrak
Penelitian dan pengembangan ini bertujuan menghasilkan hypertext wahana komunikasi sains kearifan lokal Bali (SKLB) yang efektif. Penelitian tahun/tahap kedua ini melakukan identifikasi lanjut dan perluasan isi hypertext SKLB kedalam rancangan yang dihasilkan pada penelitian tahun pertama dan validasi kemudahan akses dan efektifitas komunikasi hypertext SKLB secara on-line (internet) berdasarkan tanggapan pengunduh. Penelitian berhasil menambahkan enam konsep utama dan sejumlah sub-ordinat dan memutahirkan program hypertext SKLB sehingga hypertext SKLB total menyajikan database 52 konsepsi (9 konsep utama dan 43 konsep sub-ordinat). Mayoritas pengunduh dari berbagai kalangan (siswa SMP dan SMA, mahasiswa, guru IPA, dan masyarakat umum) memberikan tanggapan positif terhadap aspek-aspek isi dan tampilan hypertext SKLB. Hypertext SKLB dapat diunduh baik dari kota kabupaten, kecamatan, dan desa di Bali yang dijangkau handphone dan menunjukkan kinerja cukup baik.
\end{abstract}

Kata kunci: hypertext, sains kearifan lokal Bali, unit database, peta konsep, dan konsepsi

\begin{abstract}
The research and development proposed to create an on-line hypertext as an effective Balinese local genius science (SKLB) communication media. This second year research conducted further identification the SKLB content and updating the extended content into the SKLB hypertext using design created in the first year research, and examined accessibility and effectiveness of SKLB hypertext communication to various users. This second year research were success to extent six main concepts and a number of sub-ordinate concepts and updated the SKLB hypertext with the extended content up to total 52 conceptions (including 9 nine main concepts and 43 sub-ordinate concepts). Majority of various users (middle school and secondary school students, university students, science teacher, and others) gave positive appreciation to the program. The SKLB hypertext was successfully accessed in towns and villages in Bali which have telephone (HP) access.
\end{abstract}

Keywords: hypertext, Balinese local genius science, database unit, concept map, and conception 


\section{PENDAHULUAN}

Integrasi sains kearifan lokal Bali (SKLB) dengan sains modern sejalan dengan pandangan sains postmodern yang memandang sains sebagai cultural and theoretical construct (Steven Best and Douglas Keller dalam Boje, 1999). Rancangan komunikasi SKLB berbasis database yang telah dihasilkan Sudria dan Setemen (2009) perlu dilanjutkan dan diperluas isinya untuk mendukung pembangunan daerah berkesinambungan berwawasan global yang berkearifan lokal (globally think and locally act).

Komunikasi SKLB melalui hypertext on-line (internet) dengan memanfaatkan kemajuan teknologi komunikasi dan teknolgi (TIK) diperlukan untuk mengatasi kelambatan sistem komunikasi secara tradisional melalui keterlibatan langsung komunikan dalam kegiatan adat atau agama yang kurang melibatkan remaja dan generasi muda. Wahana komunikasi SKLB melalui hypertext on-line sangat dibutuhkan untuk mendukung kesadaran penggalian sains kearifan lokal Bali yang sudah mulai tumbuh dan cendrung berkembang seperti yang diungkapkan oleh Suja, Sudria, dan Muderawan (2007), tetapi belum dikomunikasikan secara sistematis, khususnya kepada generasi muda. Banyak web site di internet yang memiliki informasi yang penting dan berguna, tetapi tidak memiliki struktur yang baik sehingga memusingkan pengunjung (Tim Training SMK-TI, tt.). Kehadiran peta konsep dan kemasan informasi dalam bentuk unit-unit database konsep SKLB menyajikan informasi secara lebih terstruktur. Variasi teknik penelusuran informasi dalam tayangan hypertext akan lebih menarik minat pengguna untuk menelusri informasi.
Identifikasi dan inventarisasi lanjut sains kearifan lokal Bali serta penyajiannya dalam bentuk database secara sistematis yang mudah dan cepat diunduh perlu terus dilakukan dan dikomunikasikan kepada masyarakat melalui wahana yang efektif sesuai jaman. Cakupan materi yang luas dalam program on-line umumnya memperlambat pengunduhan. Pembatasan cakupan peta konsep dan sistem tayangan hypertext on-line perlu diatur untuk tetap menjaga kecepatan pengunduhan informasi. Demikian juga rincian deskripsi konsepsi dari unit-unit darabase hendaknya tidak terlalu singkat dan tidak terlalu panjang.

Konsepsi sebagai unit database SKLB perlu didukung oleh kajian sains modern sehingga memberikan manfaat mutualistik dalam belajar sains di sekolah. Suja, Sudria, dan Muderawan (2007) dan Anggreni (2008) telah mencoba mengindentifikasi dan mengintegrasi sains aspek kimia tradisional Bali dengan sains sekolah untuk SMP dan menemukan terdapat kemiripan misalnya dalam penggolongan aspek kajian sains yaitu yaitu prameya (objek sains asli), pramana (proses sains asli), dan susila (nilai sains asli). Ketiga katagori ini sesuai dengan bidang kajian ilmu pengetahuan (sains Barat), yakni objek pengetahuan atau sains sebagai produk, cara pengetahuan tersebut diperoleh atau sains sebagai proses, dan untuk apa pengetahuan tersebut atau nilai sains (Suriasumantri, 2005).

Kajian sains di sekolah dibedakan atas sains hidup dan lingkungannya (Biologi), energi dan perubahannya (Fisika), materi dan sifatnya (Kimia), sains Bumi dan Antariksa (IPBA). Keempat bidang sains tersebut masih bisa disederhanakan atas sains hidup (Biologi), sains energi dan perubahannya (Fisika), dan sains materi dan sifatnya (Kimia). Pengelompokan sains 
dalam masing-masing bidang juga dilakukan lebih lanjut seperti terdapat kimia organik (alami dan sintetik) dan kimia anorganik atau botani dan zoologi dalam Biologi. Pengelompokan demikian hanya untuk lebih mendalami pemahaman spesifikasi sains (diversity of nature). Ketiga aspek kajian sains prameya (objek sains asli), pramana (proses sains asli), dan susila (nilai sains asli) terdapat pada masing-masing kajian bidang sains. Tersedianya cara penggolongan secara sistematis seperti penggolongan bidang-bidang sains (sains hidup, energi, serta materi dan sifatnya) dan aspek kajian prameya, pramana, dan susila berkontribusi pada efektifitas pola organisasi konsepsi dari unit database SKLB secara sistematis, sehingga mempermudah pemahaman.

Sebagai fenomena alam, bidangbidang kajian sains tidak terpisah-pisah, namun menjadi satu kesatuan saling bergantung (unity of nature) dan menuntut pemaknaan sains secara terpadu antar bidang-bidang sains (diversity of nature). Menyajikan informasi dalam bentuk database yang mengakomodasi kedua kepentingan diversity in unity dan unity in diversity sulit dilakukan sebelum era teknologi informasi dan komunikasi (TIK). Kehadiran peta konsep dan TIK yang sudah cukup maju melalui fasilitas hypertext yang memberdayakan teknik hyperlink memungkinkan untuk membuat database dan komunikasinya secara sistematis yang mudah diakses dan penawaran penelusuran informasi dengan cepat.

Kejelasan peta konsep berperan penting dalam mewujudkan database yang sistematis dan efektif. Suatu konsep dapat merupakan sub-konsep dari konsep yang lebih superior. Herron (1977) mengungkapkan kaitan konsep atas konsep supraordinat (melingkupi konsep yang lebih spesifik), konsep ordinat (konsep-konsep yang setara/ sejajar), dan konsep subordinat (konsep yang dilingkupi). Organisasi konsep dapat dikemas sesuai hirarki konsep. Tingkat spesifikasi/generalitas tampilan informasi dalam halaman-halaman tayangan (form) dapat disesuaikan dengan tingkat generalitas konsep untuk meningkatkan kepraktisan penggunaan database. Peta konsep dalam bidang kajian akan memfasilitasi penyajian atau penelusuran informasi secara sistematis sesuai hiraki konsep dalam suatu bidang kajian. Deskripsi informasi dalam database dapat dikemas dalam satuan konsep atau unit informasi. Deskripsi konsep secara komprehensif yang mencakup aspek prameya, pramana, dan susila akan meningkatkan kebermaknaan konsepsi.

Penyajian atau penelusuran informasi antar bidang sains dalam rangka memfasilitasi keterpaduan informasi bidangbidang sains terkait untuk keutuhan kajian sains dilakukan dengan teknik hyperlink (oncclick atau penelusuran kata) antar unit-unit database. Database dikemas dalam bentuk format tertentu dan disajikan melalui hypertext agar siap disajikan dalam sistem web untuk didesiminasikan melalui sistem on-line yang dapat dan mudah diakses oleh masyarakat luas.

Penelitian tahun/tahap kedua ini bertujuan memecahkan beberapa masalah. Pertama, keberadaan SKLB yang belum diakomodasi dan kemudahannya ditambahban (update) ke dalam hypetxt hasil penelitian tahun pertama. Kedua, keajegan kinerja hypertext dalam konteks kecepatan pengunduhan program terhadap perluasan atau perluasan dan pemutahiran isi SKLB. Ketiga, tanggapan pengguna/pengunduh terhadap program 
komunikasi SKLB melalui media hypertext yang dikembangkan untuk menjastifikasi urgensi dari program.

\section{METODE PENELITIAN}

Penelitian multi tahunini secara keseluruhan berupa penelitan dan pengembangan ( $R$ \& $D)$. Usulan penelitian tahun pertama (tahun 2009) telah menghasilkan prototif model hypertext SKLB, tetapi dengan isi terbatas dan belum diuji desiminasi. Usulan penelitian tahap kedua (2011) ini adalah melanjutkan penelitian tahap pertama (2009) yakni memperluas cakupan isi (menambah topiktopik) SKLB, menganalisis kemampuan program hypertext dimutahirkan (update), dan validasi uji desiminasi SKLB melalui sistem on-line web kepada masyarakat (siswa, mahasiswa, dan masyarakat umum). Alur keseluruhan penelitian disajikan secara diagramatik dalam Gambar 1.

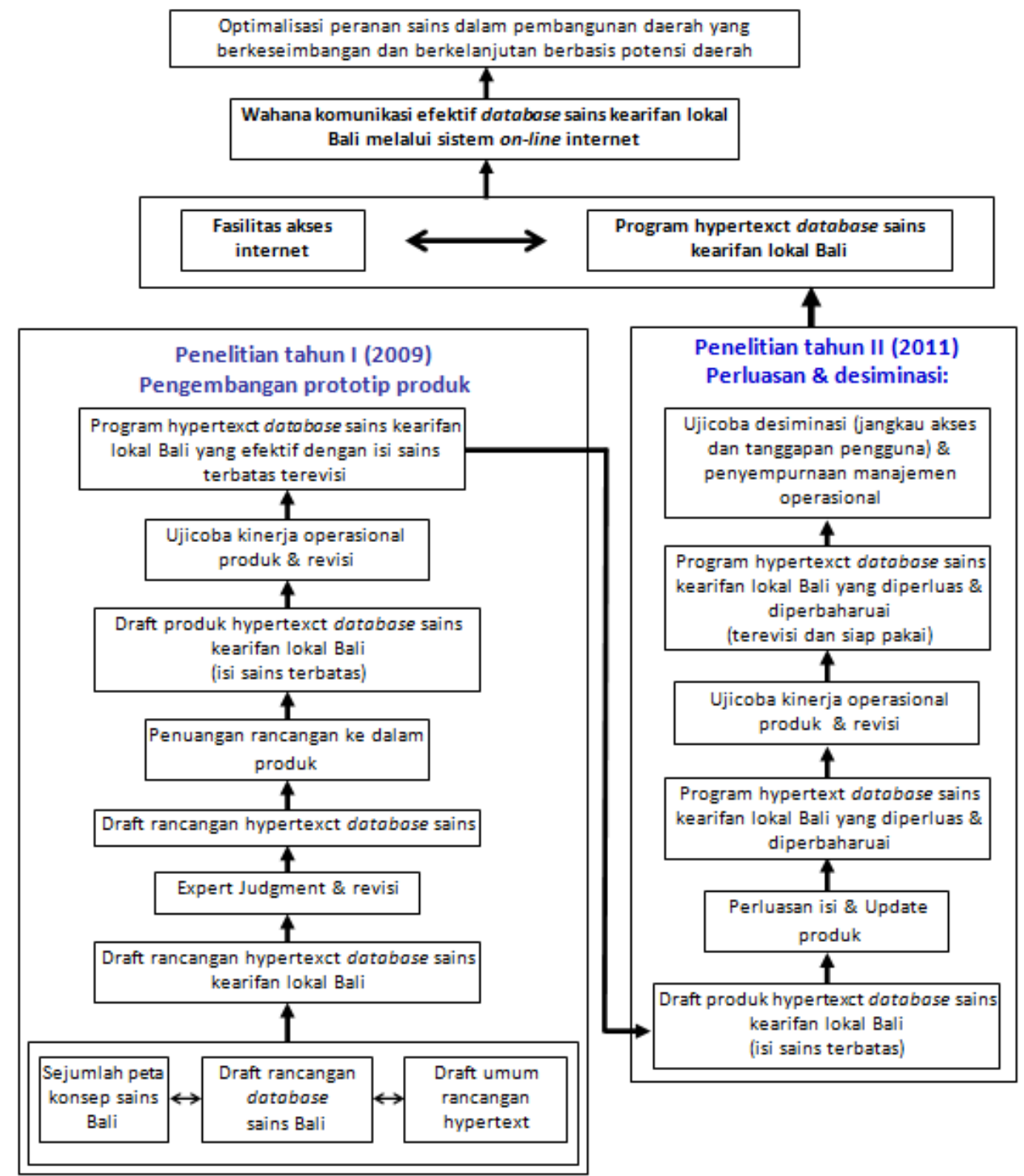


Aspek yang diteliti, pelaksana, luaran, dan indikator hasil penelitian untuk tahap kedua (tahun 2011) disajikan dalam Tabel 1. Analisis data hasil penelitian dilakukan secara deskriptif.

Tabel 1 Aspek yang diteliti, Obyek, Luaran, dan Indikator Hasil Penelitian

\begin{tabular}{|c|c|c|c|}
\hline Aspek yang Diteliti & Objyek & Luaran & Indikator \\
\hline $\begin{array}{l}\text { - Perluasan isi } \\
\text { (penambahan topik-topik) } \\
\text { SKLB, peta konsep, dan } \\
\text { unit-unit database konsep- } \\
\text { konsep sains yang } \\
\text { membangunnya }\end{array}$ & $\begin{array}{l}\text { - Keberadaan, kedalaman } \\
\text { SKLB, dan sinerginya } \\
\text { dengan sains sekolah } \\
\text { - Variasi keabstrakan konsep, } \\
\text { posisi konsep, dan } \\
\text { keterkaitan antar konsep } \\
\text { - Kelengkapan dan kedalaman } \\
\text { informasi dari konsep (unit- } \\
\text { unit database serta kualitas } \\
\text { tampilannya }\end{array}$ & $\begin{array}{l}\text { - Topik-topik SKLB } \\
\text { tambahan, peta } \\
\text { konsep, dan } \\
\text { deskripsi dari unit- } \\
\text { unit konsep } \\
\text { database }\end{array}$ & $\begin{array}{l}\text { - Berhasil mengidentifikasi dan/ } \\
\text { atau mengidentifikasi sejumlah } \\
\text { topik SKLB tambahan, peta } \\
\text { konsep, deskripsi unit-unit konsep } \\
\text { database yang membangunnya } \\
\text { - Jumlah topik dan konsep-konsep } \\
\text { yang berhasil diinventaris } \\
\text { dan/atau diidentifikasi (5-8 topik } \\
\text { lagi) } \\
\text { - Kualitas peta konsep (kebenaran } \\
\text { dan memeprmudah pemahaman) }\end{array}$ \\
\hline $\begin{array}{l}\text { - Menyiapkan rancangan } \\
\text { hypertext untuk } \\
\text { mengakomodasi } \\
\text { tambahan isi SKLB } \\
\text { - Update isi SKLB (topik, } \\
\text { petakonsep, dan unit-unit } \\
\text { database SKLB ke dalam } \\
\text { rancangan hypertext }\end{array}$ & $\begin{array}{l}\text { - Memfasilitasi kecepatan } \\
\text { akses unit-unit database } \\
\text { - Adaptibilitas rancangan } \\
\text { hypertext } \\
\text { - Kinerja fungsional } \\
\text { komponen-komponen } \\
\text { hypertext }\end{array}$ & $\begin{array}{l}\text { - Produk hypertext } \\
\text { SKLB yang } \\
\text { diperluas } \\
\text { (diupdate) }\end{array}$ & $\begin{array}{l}\text { - Keberhasil (kemudahan/ } \\
\text { kelancaran) disain hypertext } \\
\text { mengakomodasi penambahan isi } \\
\text { (topik-topik) SKLB } \\
\text { - Jumlah tambahan topik SKLB } \\
\text { yang efektif di akomodasi oleh } \\
\text { disain hypertext }\end{array}$ \\
\hline $\begin{array}{l}\text { - Uji kinerja fungsional } \\
\text { (operasional) dan revisi } \\
\text { program }\end{array}$ & $\begin{array}{l}\text { - Kelancaran akses informasi } \\
\text { dalam hypertext } \\
\text { - Kerumitan/kesederhanaan } \\
\text { unit-unit database SLLB } \\
\text { - Daya tarik tampilan }\end{array}$ & $\begin{array}{l}\text { - Produk dengan } \\
\text { kinerja fungsional } \\
\text { secara efektif }\end{array}$ & $\begin{array}{l}\text { - Kelancaran kinerja hypertext } \\
\text { - Sinergy kinerja kompponen- } \\
\text { komponen hypertext mendukung } \\
\text { penyajian informasi secara efektif } \\
\text { - Program hypertext yang terevisi } \\
\text { (siap uji disiminasi) }\end{array}$ \\
\hline $\begin{array}{l}\text { - Uji disiminasi produk } \\
\text { hypertext yang telah } \\
\text { diperluas dan revisi }\end{array}$ & $\begin{array}{l}\text { - Dukungan kualitas sarana } \\
\text { akses internet } \\
\text { - Tanggapan pengguna } \\
\text { terhadap kualitas isi, } \\
\text { kegunaan (seperti dukungan } \\
\text { pemahaman sains sekolah), } \\
\text { daya tarik, dan kecepatan } \\
\text { akses program) }\end{array}$ & $\begin{array}{l}\text { - } \text { Program } \\
\text { hypertext yang } \\
\text { diperluas }\end{array}$ & $\begin{array}{l}\text { - Kemudahan akses } \\
\text { - Tanggapan masyarakat (siswa, } \\
\text { mahasiswa, dan masyarakat } \\
\text { umum) terhadap progran } \\
\text { hypertext yang dihasilkan }\end{array}$ \\
\hline - Frevisi akhir program & $\begin{array}{l}\text { - Kinerja komponen-komponen } \\
\text { hypertext dan/atau sistem } \\
\text { pengelolaan web site yang } \\
\text { direvisi }\end{array}$ & $\begin{array}{l}\text { - Hypertext wahana } \\
\text { SKLB on-line }\end{array}$ & $\begin{array}{l}\text { - Kemudahan akses } \\
\text { - Tanggapan masyarakat (siswa, } \\
\text { mahasiswa, dan masyarakat } \\
\text { umum) terhadap progran } \\
\text { hypertext yang dihasilkan }\end{array}$ \\
\hline
\end{tabular}

HASIL PENELITIAN

Hasil penelitian ini berupa konsepkonsep sains kearifan lokal Bali (SKLB) yang berhasil diinventaris dari berbagai sumber dan lapangan, sejumlah peta konsep, deskripsi unit-unit konsep (database), tampilan informasi SKLB dalam web, dan tanggapan pengguna (pengakses) terhadap tampilan hypeertext dalam internet. 
Hasil penelitian dari berbagai sumber ditemukan keberadaan konsep sains kearifan lokal Bali (SKLB) cukup banyak. Banyak konsep yang mempunyai hubungan hirarkis supraordinate. ordinate, dan subordinate sehingga memungkinkan disajikan dalam bentuk peta konsep. Konsep-konsep utama SKLB yang sudah berhasil diinventaris seperti tri hita karana, subak, panca sarada, panca mahabhuta, catur purusa artha, catur pramana, arsitektur tradisional Bali, ngaben, mecaru, panca datu, perunggu, dan gamelan. Tiga konsep utama dan peta konsepnya serta konsepkonsep sub-ordinatnya telah dihasilkan dalam penelitian tahun pertama (2009). Penelitian tahun kedua (2011) berhasil menambahkan enam peta konsep lagi yang mencakup dua level konsep-konsep subordinat dan merumuskan konsepsi dari konsep-konsep tersebut. Keseluruhan sudah dihasilkan sembilan peta konsep dan sejumlah konsep sub-ordinat serta deskripsi (konsepsi) dari masing-masing konsep tersebut (unit unit database). Konsepkonsep tersebut disajikan dalam Tabel 2.

Tabel 2. Temuan Sementara Sejumlah Konsep dan Konsep Subordinat SKLB

\begin{tabular}{|l|l|l|}
\hline No & \multicolumn{1}{|c|}{ Konsep } & \multicolumn{1}{|c|}{ Konsep Subordinat } \\
\hline 1 & ngaben & $\begin{array}{l}\bullet \text { panca mahabuta } \\
\bullet \text { punarbawa/reinkarnsi/s } \\
\text { amsara }\end{array}$ \\
\hline 2 & catur pramana & $\begin{array}{l}\bullet \text { pratyaksa } \\
\bullet \text { anumana: } \\
\bullet \text { upamana } \\
\bullet \text { sabda }\end{array}$ \\
\hline 3 & $\begin{array}{l}\text { arsitektur tra- } \\
\text { disional Bali }\end{array}$ & $\begin{array}{l}\bullet \text { asta kosala } \\
\text { asta bumi }\end{array}$ \\
\hline 4 & panca datu & $\begin{array}{l}\bullet \text { emas (kuning) } \\
\bullet \text { perak (putih } \\
\text { tembaga (merah) } \\
\bullet \text { besi (hitam) } \\
\bullet \text { timah/stanum (abu-abu) }\end{array}$ \\
\hline
\end{tabular}

\begin{tabular}{|c|c|c|}
\hline No & Konsep & Konsep Subordinat \\
\hline 5 & caru & $\begin{array}{l}\text { - segehan } \\
\text { - caru ekasato } \\
\text { - caru manca } \\
\text { - tawur }\end{array}$ \\
\hline 6 & $\begin{array}{l}\text { panca } \\
\text { mahabhuta }\end{array}$ & $\begin{array}{l}\text { - apah } \\
\text { - teja } \\
\text { - wayu } \\
\text { - akasa } \\
\text { - pertiwi }\end{array}$ \\
\hline 7 & perunggu & $\begin{array}{l}\text { - gamelan } \\
\text { - bokor } \\
\text { - kerajinan logam }\end{array}$ \\
\hline 8 & subak & $\begin{array}{l}\text { - fasilitas } \\
\text { - pura subak } \\
\text { - krama subak }\end{array}$ \\
\hline 9 & tri hita karana & $\begin{array}{l}\text { - parahyangan } \\
\text { - pawongan } \\
\text { - palemahan }\end{array}$ \\
\hline
\end{tabular}

Peta konsep dibuat sesuai dengan temuan rancangan peta konsep yang dihasilkan pada penelitian tahun pertama yakni sampai tiga level untuk kemudahan pengelolaan dan kecepatan diunduh oleh pengguna ketika di dimuat dalam web site. Penelitian ini diarahkan untuk mebangun

sistem komunikasi sains kearifan lokal Bali yang edukatif melalui wahna hypertext berbasis database yang mudah dikelola terutama dalam perluasan (updating) isi/konsep SKLB, efektif, penelusuran informasi cepat, dan menarik perhatian pengguna. Contoh peta konsep SKLB yang 
berhasil dikembangkan tahun 2011 dan dua sebuah peta konsep sebagai berikut.

contoh konsepsi (unit database) dalam

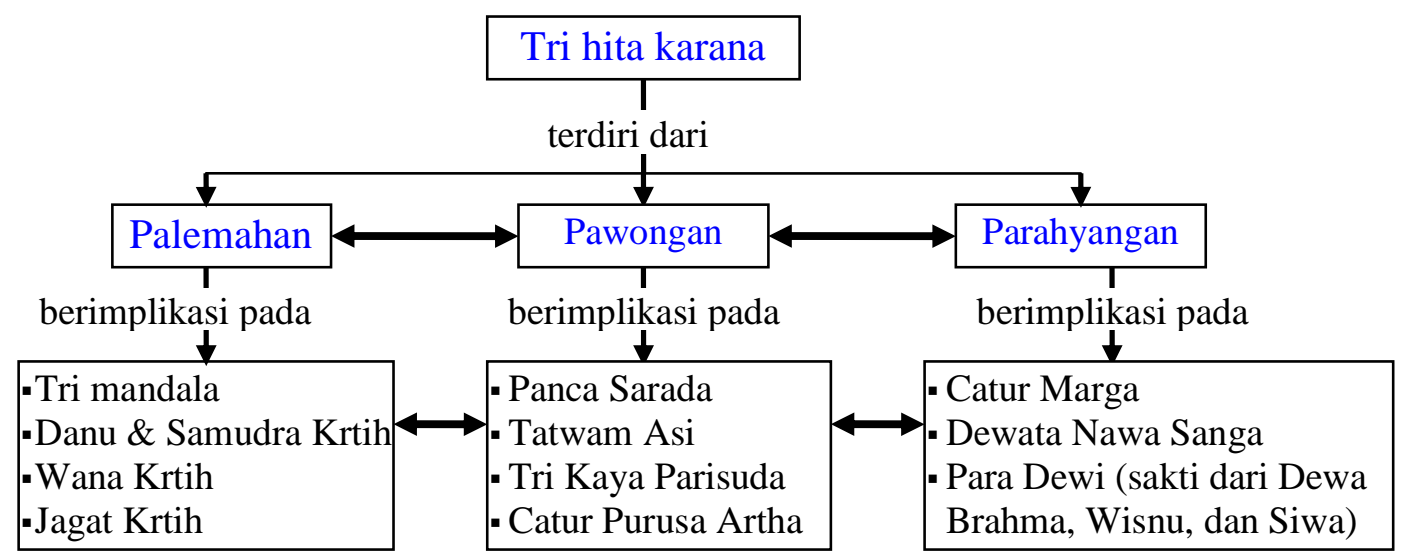

Tri hita karana adalah tiga sumber yang mendatangkan keselamatan atau kebaikan (Ragam Istilah Hindu, Tim Bali Age, 2011:) yakni hubungan baik antara manusia dengan Tuhan (parahyangan), antara manusia dengan manusia (pawongan), antara manusia dengan lingkungan (palemahan). Perpaduan ketiga aspek keseimbangan merupakan sistem keharmonisan hidup (lahir dan batin). Tri hita karana didasarkan pada keyakinan bahwa alam semesta beserta isinya diciptakan, dipelihara dan dipralina (dilebur) oleh Tuhan sebagai Tri Murti (Dewa Brahma, Wisnu, dan Siwa) yang mempunyai kekuatan Tri Kona yakni upeti (penciptaan) oleh dewa Brahma, setiti (pemelihara) oleh Dewa Wisnu, dan pralina (pelebur) oleh dewa Siwa. Siklus lahir (upeti), hidup (setiti), dan pralina (mati) terusberjalan (reinkarnasi/punarbawa) hingga ciptaan kembali menyatu dengan penciptanya. Berbagai konsep lain yang mendukung tri hita karana antara lain: Catur Marga/Yoga, Dewata Nawa Sanga, Dewi-Dewi sebagai sakti dari Dewa Brahma, Wisnu, dan Siwa (seperti Dewi Saraswati, Dewi Uma/Sri, dan Dewi

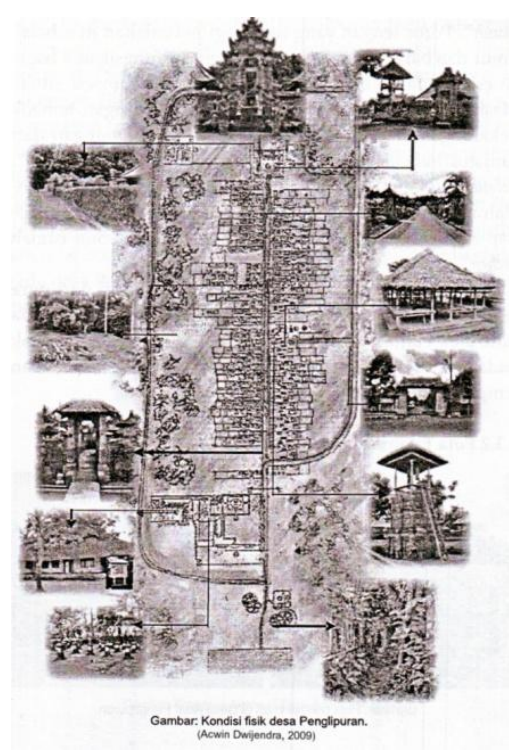
Parwati), Panca Sarada (kepercayaan terhadap Tuhan, atman, karma pala, samsara, dan moksa), tiga kerangka dasar masyarakat Bali Hindu (tatwa, susila, upakara), Tat wam Asi, Tri Kaya Parisuda, dan Catur Purusartha. Sukardana (2010) lebih jauh menjabarkan keterkaitan ketiga kerangka dasar tersebut terhadap hampir semua konsep penataan kehidupan masyarakat Bali Hindu. Konsep tri hita karana mengakomodasi pandangan sains postmodern sebagai kritik terhadap sains modern (Barat). Sains modern memandang sains bebas nilai (kearifan budaya), lebih mengarah pada ekploitasi, dan telah banyak berdampak 
pada ketidakseimbangan dengan lingkungan. Capra (1982) mengkritik pengembangan energi nuklir yang lebih banyak berdampak merugikan. Sementara sains postmodern memandang bahwa persepsi orang terhadap alam (sains) tidak terlepas dari konteks budayanya (Best \& Kellner dalam Boje, 1999).

Pawongan dalam tri hita karana merupakan keharmonisan hubungan manusia dengan manusia. Konsep pawongan memandang kedudukan manusia sama dihadapan Tuhan. Semua manusia mempunyai hak untuk mendapatkan kesejahtraan hidup (Jagadita) dan mencapai penyatuan diri dengan Tuhan (moksa). Jiwa/rokh/atman semua mahluk pada dasarnya sama, tetapi tingkat kebesannya atau kemuliannya bergantung pada karma mahluk hidup yang ditempati (mewadahi). Manusia lahir (bereinkarnasi) berulang-

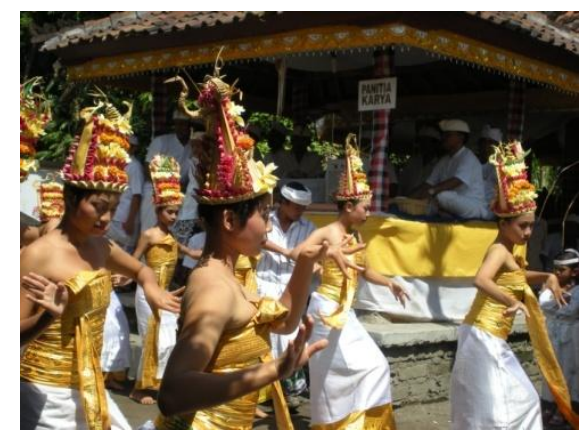
ulang sebagai kesempatan untuk memperbaiki karmanya untuk dapat mencapai tujuan akhir yakni bersatu dengan sang Pencipta (Tuhan). Aktifitas hubungan antar manusia baik secara langsung maupun tidak langsung merupakan satu bentuk wahana berkarma. Susila sebagai satu komponen tiga kerangka dasar masyarakat Hindu Bali mengatur berbagai konsep berkarma yang baik seperti konsep tat twan asi, tri kaya parisuda, catur purusartha, yama niyama brata, dan dasa dharma (Sukardana, 2010). Kesadaran terhadap perlunya hubungan harmoni antar manusia berbagai wadah sosial atau kesepakatan masyarakat berkembang di Bali antara lain desa pakraman, dadia, sekeha subak, awig-awig desa atau sekeha yang pada umumnya dapat disesuaikan dengan perkembangan jaman. Banyak bentuk kegiatan sosial di Bali seperti penyelenggaraan hampir semua upacara yadnya, kesenian, dan berbagai paruman. Bebera fasilitas yang mendukung aktivitas sosila di Bali antara lain keberadaan tempat pertemuan krama/warga (seperti wantilan desa, bale dadia, dan bale subak) dan kegiatan seperti sangkep (pertemuan anggota) dan hampir semua kegiatan yadnya (seperti ngaben, pawiwahan, dan piodalan di pura).

Hypertext dibuat sesuai rancangan yang dihasilkan pada penelitian tahap I (2009) dan ditambahkan rincian sub-konsep pada kolom navigasi konsep utama SKLB. Hypertext dalam penelitian ini mengikuti model hypertext perpaduan page-based browser dan concept map-based interfase yang memfasilitasi variasi sistem navigasi informasi (navigasi) yakni penelusuran kata (search), on-click pada konsep dalam peta konsep maupun pada kata yang cetak biru dalam deskripsi konsepi (unit database) dengan fasilitas hyperlink. Kedalaman informasi database dibatasi sampai tiga level dengan membatasi peta konsep dan sampai pada. Tampilan informasi kinerja SKLB hypertext hasil ujicoa uplod pada web site (http://informatika.undiksha.ac.id/sklb) cukup lancar diunduh di kota kabupaten, kota kecamatan, maupun desa sepanjang signal telepon dapat ditangkap melalui telepone genggam/modem dengan kecepatan relatif normal pada periodeperiode waktu tertentu.

Ringkasan tanggapan pengunduh terhadap aspek-aspek penting dalam 
program hypertext komunikasi SKLB disajikan dalam Tabel 3. Mayoritas pengunduh memberikan tanggapan positif terhadap program komunikasi SKLB melalui hypertext on-line yang dikembangkan dalam penelitian di atas, meskipun beberapa siswa SMP memberi komentar agar penggunaan bahasa disederhanakan.

Tabel 3 Tanggapan Pengunduh Program Hypertext Komunikasi SKLB

\begin{tabular}{|c|c|c|c|c|c|c|c|c|c|c|c|c|c|c|c|c|}
\hline \multirow{3}{*}{ No } & \multirow{3}{*}{ Uraian } & \multicolumn{12}{|c|}{ Jumlah Responden Berpendapat } & \multicolumn{3}{|c|}{ Total } \\
\hline & & \multicolumn{2}{|c|}{ SMP } & \multicolumn{2}{|c|}{ SMA } & \multicolumn{2}{|c|}{ Mhs } & \multicolumn{2}{|c|}{ GIPA } & \multicolumn{2}{|c|}{ PB } & \multicolumn{2}{|c|}{ Lain } & \multirow{2}{*}{$B / S$} & \multirow{2}{*}{$\mathrm{R}$} & \multirow{2}{*}{$\mathrm{K}$} \\
\hline & & ${ }^{*} \mathrm{~B}$ & $\mathrm{~K}$ & $\mathrm{~B}$ & $\mathrm{~K}$ & $B$ & $\mathrm{~K}$ & $B$ & $\mathrm{~K}$ & $\mathrm{~B}$ & $\mathrm{~K}$ & $\mathrm{~B}$ & $\mathrm{~K}$ & & & \\
\hline \multirow[t]{10}{*}{1} & Konsep-konsep SKLB & & & & & & & & & & & & & & & \\
\hline & $\begin{array}{l}\text { a. Banyak konsep (pengetahuan) SKLB yang perlu } \\
\text { dipahami }\end{array}$ & 2 & 2 & 12 & & 7 & & 2 & & & & & & 23 & 15 & 2 \\
\hline & $\begin{array}{l}\text { b. Deskripsi/penjelasan isi (konsepsi) unit-unit } \\
\text { database SKLB (tanpa didukung penjelasan sains } \\
\text { modern) sudah jelas }\end{array}$ & 1 & & 10 & 2 & 4 & 1 & 2 & & 1 & & 1 & & 19 & 17 & 3 \\
\hline & $\begin{array}{l}\text { c. Deskripsi isi (konsepsi) unit-unit database SKLB } \\
\text { yang didukung dengan kajian sains modern } \\
\text { diperlukan untuk (pilih satu dan beri penilaian } \\
\text { pilihan tersebut): }\end{array}$ & & & & & & & & & & & & & & & \\
\hline & b1. pemahaman konsep SKLB saja & 1 & & 6 & & 1 & & 1 & & 1 & & & & 9 & 3 & 0 \\
\hline & b2. pemahaman konsep sains modern saja & & & 2 & & 2 & & 2 & & & & & & 6 & 5 & 0 \\
\hline & $\begin{array}{l}\text { b3. pemahaman konsep SKLB maupun konsep } \\
\text { sains moder terkait }\end{array}$ & 2 & & 16 & 1 & 7 & & 3 & & & & 1 & & 29 & 6 & 1 \\
\hline & $\begin{array}{l}\text { d. Penjelasan sains modern mendukung penje- } \\
\text { lasan/deskripsi isi unit-unit database konsep SKLB } \\
\text { adalah jelas }\end{array}$ & 3 & & 14 & & 5 & & & & & & & & 22 & 17 & 0 \\
\hline & $\begin{array}{l}\text { e. Peta konsep penting untuk mempermudah/ } \\
\text { mempercepat pemahaman SKLB }\end{array}$ & 3 & 2 & 15 & 1 & 5 & & 3 & & & & & & 26 & 10 & 3 \\
\hline & $\begin{array}{l}\text { f. Peta konsep menyajikan cakupan konsep SKLB } \\
\text { cukup komprehensip (berisi aspek-aspek yang } \\
\text { semestinya terlingkupi seperti aspek } \\
\text { pengetahuan/tatwa, prilaku/prosedur /susila, } \\
\text { dan/atau sarana/upakara) }\end{array}$ & 3 & & 15 & 1 & 5 & & 2 & 1 & & & 1 & & 26 & 13 & 2 \\
\hline \multirow[t]{7}{*}{2} & Tampilan informasi & & & & & & & & & & & & & & & \\
\hline & a. Menarik & & 1 & 13 & 2 & 1 & & & & 1 & & & 1 & 15 & 22 & 4 \\
\hline & $\begin{array}{l}\text { b. Panjang penjelasan (deskripsi) untuk satu unit } \\
\text { konsep/sub-konsep adalah cukup (tidak terlalu } \\
\text { singkat atau tidak terlalu panjang) }\end{array}$ & 2 & & 14 & 1 & 4 & 1 & 3 & 1 & & & & & 23 & 13 & 3 \\
\hline & $\begin{array}{l}\text { c. Ilustrasi gambar/foto cukup (tidak berlebihan } \\
\text { sehingga tidak lama diungguh / download atau } \\
\text { terbuka/muncul) }\end{array}$ & 3 & 1 & \begin{tabular}{|l}
14 \\
\end{tabular} & 1 & \begin{tabular}{|l|}
7 \\
\end{tabular} & & & & & & & 1 & 24 & 14 & 3 \\
\hline & $\begin{array}{l}\text { d. Perlu dilengkapi rekaman dinamik/film pendek jika } \\
\text { obyek berupa peristiwa, tetapi panjang rekaman < } \\
2 \text { menit) agar tidak lama diungguh }\end{array}$ & 3 & 1 & 15 & 1 & \begin{tabular}{|l}
7 \\
\end{tabular} & & 1 & 2 & & & & 1 & 26 & 12 & 5 \\
\hline & $\begin{array}{l}\text { e. Tayangan hendaknya dibatasi pada deskripsi satu } \\
\text { sub-konsep, namun peta konsep yang memayungi } \\
\text { konsep tersebut harus disertakan }\end{array}$ & \begin{tabular}{|l|}
4 \\
\end{tabular} & 1 & \begin{tabular}{|l}
16 \\
\end{tabular} & & \begin{tabular}{|l}
5 \\
\end{tabular} & & 2 & & & & 1 & & \begin{tabular}{|l|}
28 \\
\end{tabular} & 9 & 1 \\
\hline & $\begin{array}{l}\text { g. Disediakan file dokumen yang dapat } \\
\text { diungguh/download. }\end{array}$ & 4 & 1 & 18 & 1 & 6 & 1 & 2 & 1 & & & 1 & & 31 & 4 & 4 \\
\hline
\end{tabular}

${ }^{*} \mathrm{~B}=$ baik (setuju);

$\mathrm{K}=$ kurang (tidak setuju);

$\mathrm{R}=$ ragu (sedang) 


\section{PEMBAHASAN}

Penelitian ini telah berhasil mengidentifikasi sejumlah konsep utama dan sub-konsep SKLB, membuat peta konsep, merumuskan konsepsi (unit-unit database), membuat dan mengelola program hypertext komunikasi SKLB, meskipun tampilan dan variasi sistem penelusuran informasi secara efektif masih perlu disempurnakan. Secara umum kehadiran program hypertext komunikasi sains kearifan lokal Bali (SKLB) yang dibuat dalam penelitian ini dapat diunduh baik dari kota kabupaten, kota kecamatan, maupun desa yang sudah terjangkau signal handphone (HP). Seperti pada umumnya, kecepatan akses tergantung pada periode waktu yakni pagi (sebelum pukul 09.00) dan malam (setelah pukul 24.00) cepat. Sementara kecepatan akses antara pukul 9.00 - 24.00 cendrung tergolong sedang. Masyarakat Bali secara keseluruhan terutama yang berpendidikan SMP ke atas secara mayoritas memberikan tanggapan positif (baik/setuju) terhadap aspek-aspek yang disajikan/dikembangkan dalam hypertext SKLB ini dan adanya permintaan sajian informasi SKLB secara lebih lengkap yang disertai dengan rekaman agar lebih menarik dan penyediaan file yang dapat diunduh.

Perbandingan pengunduh yang mengakui dan tidak mengakui bahwa banyak konsep SKLB yang perlu dipahami adalah 23:1. Pengakuan ini mengindikasikan masyarakat perlu mengetahui dan memahami sains kearifan lokalnya untuk pembangunan daerah yang berkesinambungan (sustainable). Produk 43 unit konsep (database) yang terdiri dari 9 konsep utama dan 34 sub-konsep serta keterkaitannya melalui sembilan peta konsep yang sudah berhasil dirumuskan cukup memberi gambaran kepada masyarakat tentang kekayaan SKLB. Penyediaan beberapa konsep yang telah diidentifikasi, namun belum dibuatkan deskripsi (konsepsinya) dalam hypertext ini dapat mengajak masyarakat turut aktif memikirkan pengembangannya dan menyadari masih banyak SKLB yang belum teridentifikasi. Hal demikian terindikasi dalam permintaan mereka untuk melengkapi deskripsi konsep-konsep tersebut.

Masyarakat (pengunduh) mengakui pentingnya kehadiran peta konsep. Peta konsep memberi gambaran keluasan cakupan konsep-konsep utama dan mempermudah/ mempercepat pemahaman konsep tersebut secara komprehensif. Kehadiran peta konsep dalam tayangan informasi dalam mampu memfasilitasi variasi sistem penelusuran informasi untuk lebih meningkatkan keberhasilan dan kecepatan memperoleh informasi yang diharapkan. Di samping itu, kehadiran tayangan peta yang mengawali dan mendampingi tayangan informasi akan meningkatkan efektifitas aspek edukasi dari dari wahana komunikasi SKLB.

Deskripsi konsep sebagai unit database yang menyajikan konsepsi konsep SKLB dan dukungan kajian sains modern terhadap konsep SKLB tersebut diperlukan oleh masyarakat baik untuk pemahaman konsep SKLB dan konsep sains modern masing-masing yang terkait, maupun pemahaman kedua konsep secara mutualistik. Mayoritas pengunduh menyatakan integrasi SKLB dan sains modern dalam deskripsi/konsepsi konsep (unit database) penting untuk pemahaman 
SKLB dan sains modern secara mutualisme dengan rasio pengunduh yang mendukung terhadap yang kurang dan tidak mendung 29: 1. Permintaan untuk pemberian penjelasan atau makna yang lebih rinci terhadap deskripsi konsep-konsep SKLB perlu dipertimbangkan, namun kedalaman deskripsi perlu dibatasi agar program komunikasi SKLB melaui hypertext on-line ini tidak terlalu berat untuk diungguh. Pengembangan/penyempurnaan hypertext SKLB perlu terus dilakukan. Penyediaan fasilitas hyperlink dengan sumber informasi yang lebih lengkap merupakan solusi cukup efektif terhadap masalah ini. Di samping itu, mayoritas pengunduh juga mengharapkan pengembang menyediakan file dokumen lengkap yang bisa diunduh.

$$
\text { Mayoritas pengunduh juga }
$$

memberikan komentar positif terhadap tampilan hypertext SKLB ini. Rasio komentar keseluruhan pengunduh yang menyatakan tampilan menarik, biasa saja (sedang) dan kurang menarik adalah 15: 22: 4. Komentar demikian cukup realistik mengingat tampilan perdana hypertext ini masih belum optimal seperti akses penelusuran melalui fasilitas on-click pada konsep dalam peta konsep maupun dalam uraian deskripsi konsep belum semua diaktifkan. Demikian juga tayangan informasi unit deskripsi konsep (unit database) belum semua didukung dengan gambar maupun rekaman peristiwa SKLB di masyarakat secara optimal. Penyempurnaan terhadap tampilan perdana program cendrung akan meningkatkan apresiasi masyarakat.

Tanggapan postif pengunduh terhadap program hypertext komunikasi SKLB ini secara on-line (internet) mengindikasikan dukungan mereka terhadap kajian pengembang. Kurangnya komunikasi sains kearifan lokal Bali secara efektif kepada generasi muda Bali pada khususnya dapat menyebabkan generasi muda Bali asing dengan sains kearifan lokalnya sendiri. Banyak orang muda Bali terutama diperkotaan tidak mengenal istilah Bali seperti cakangan, tengala, gau, bubu, dan cueng/blauk, lud, dan bebedag karena istilah-istilah sains lokal tersebut biasanya muncul pada masyarakat pedesaan dengan sistem kominikasi tradisional. Komunikasi tradisional cendrung tidak proaktif, menunggu orang bertanya atau orang terlibat langsung dalam aktivitas yang melibatkan sains tersebut. Sementara komunikasi kebanyakan generasi muda cenderung memanfaatkan TIK dan proaktif atau promotif.

$$
\text { Program hypertext yang }
$$

dikembangkan menawarkan sistem komunikasi SKLB secara efektif dalam jaman TIK. Model hypertext database SKLB dengan memadukan penelusuran melalui konsep utama, peta konsep, dan/atau kata kunci menawarkan variasi sistem penelusuran informasi untuk lebih meningkatkan keberhasilan dan kecepatan memperoleh informasi yang diharapkan. Di samping itu, kehadiran tayangan peta yang mengawali dan mendampingi tayangan informasi akan meningkatkan efektifitas aspek edukasi dari dari wahana komunikasi SKLB.

Kelebihan hypertext yang dihasilkan dalam penelitian dan pengembangan ini terutama pada penayangan peta konsep pada halaman tempat munculnya deskripsi konsep dan dukungan kajian sains modern yang terkait. Kehadiran tayangan peta konsep yang sesuai mengingatkan pengunduh tentang keterkaitan secara jelas konsep itu dengan konsep yang lain. Hal ini secara tidak langsung mengarahkan pembaca untuk melihat informasi lain terkait 
guna memahami konsep SKLB tersebut secara lebih komprehensip. Pembatasan peta konsep hanya sampai tiga level dan deskripsi ringkas unit database (memuat hal-hal penting saja) berkontribusi pada kelancaran akses SKLB dan kemudahan untuk memutahirkan program. Penambahan level akan membuat pekerjaan updating program lebih sulit, memperlambat akses informasi, dan akan cenderung membosankan dalam pengembangannya. Di samping itu, pemabatasan hingga tiga level juga lebih mudah menampilkan peta konsep dan lebih menarik. Tampilan hypertext penting untuk menarik pengunduh, sehingga mereka terdorong melihat informasi SKLB lebih jauh (lebih luas dan lebih mendalam) dari sumber lain yang lebih lengkap.

Model program hepertext komunikasi SKLB ini memiliki sejumlah kelemahan seperti beberapa kelemahan yang secara inflisit sudah disebutkan dalam pembahasan di atas yaitu pembatasan level jangkauan peta konsep dan muatan informasi untuk menjaga kecepatan akses, dan penyedian variasi fasilitas penelusuran (navigasi) yang menambah beban kerja dalam pemutahiran program. Penyediaan penjelasan sains modern untuk menguatkan pemahaman SKLB dan sebalik penguatan sains modern oleh deskripsi SKLB tidak selalu mudah dilakukan dan menuntut pengembang mempunyai wawasan luas dalam pemahaman SKLB maupun sains modern. Sumbangan naskah tulisan SKLB sesuai dengan format hypertext ini dari para peneliti dan pakar sains modern dan/atau SKLB sangat diperlukan dalam pemberdayaan SKLB dan sains modern dalam pembangunan sains secara kontektual dan berkelanjutan.

\section{Simpulan dan saran}

Hypertext database sains kearifan lokal Bali (SKLB) berbantuan peta konsep berhasil dikembangkan. Format database SKLB maupun peta konsep dibatasi sampai tiga level. Fasilitas variasi sistem penelusuran informasi melalui penelusuran dengan kata kunci dan fitur hyperlink pada label-label konsep dalam halaman utama maupun peta konsep menjadikan hypertext lebih menawarkan kemudahan dan kecepatan penelusuran informasi yang dapat memotivasi pengunduh memanfaatkan program. Hypertext ini menyajikan deskripsi SKLB, namun sedapat mungkin didukung oleh kajian bidang-bidang sains modern yang terkait ( aspek fisika, biologi, dan kimia secara terintegrasi) sesuai dengan jenis konsep SKLB. Rancangan format sistem database dan peta konsep yang terbatas pada tiga level secara psikologis penting (tidak membosankan) terutama bagi petugas layanan updating isi SKLB dalam perluasan cakupan isi program. Masih cukup banyak isi SKLB yang dapat dikomunikasi melalui media hypertext yang dikembangkan dalam penelitian ini. Penambahan isi enam topik hingga menjadi sembilan topik dengan total 43 unit konsep masih dapat diunduh dengan kecepatan normal oleh pengunduh baik di kota kabupaten, kota kecamatan, dan desa di Bali sepanjang akses internet tersedia di tempat itu. Masyarakat memberi tanggapan positif terhadap program hypertext SKLB yang dikembangkan.

Program hypertext database SKLB berbantuan peta konsep ini diharapkan menghantar dan merangsang pengguna (terutama generasi muda) untuk mempelajari dan memahami SKLB. Informasi atau konsepsi suatu konsep sebagai unit database SKLB sebagai satuan 
tayangan informasi dalam hypertext hendaknya diawali dengan deskripsi konsep SKLB itu (konsepsi) yang disertai dengan rujukan informasi dan ilustrasi, serta kemudian ditambahkan eleborasi yang diperkuat dengan kajian aspek-aspek sains modern untuk mengaktualisasikan konsep SKLB tersebut. Penyiapan unit informasi ini merupakan bagian kerja yang paling sulit dalam pengembangan hypertext database SKLB di atas, karena memerlukan wawasan pemahaman SKLB yang luas dan terbuka dari perumus. Agar program ini cepat berkembang menjadi wahana komunikasi SKLB yang edukatif secara efektif, kontribusi dari berbagai pihak untuk menambahkan atau memperluas isi SKLB ini sangat diperlukan. Struktur atau sistematika deskripsi atau rumusan konsepsi dalam unit informasi database di atas perlu diikuti agar mengarah pada komunikasi SKLB yang edukatif secara efektif.

\section{DAFTAR RUJUKAN}

Balasubramanian, V. (tt). The Basics of Science http://www.pustakaCommunication. deptan.go.id/rkb/know/wdgeBank/web Board/Science

Anggreni, N. K. (2008). Identifikasi Konsepkonsep Sains Kimia Asli (Indigeneus Chemistry) yang Relevan dengan Konsep-konsep Kimia dalam Pembelajaran Sains di SMP. Skripsi (tidak dipublikasikan). Singaraj: Universitas Pendidikan Ganesh

Babadbali.cm

http://www.babadbali.com/astakosalak osali/astakosala.htm. Diakses 25 Juni 2008.

Boje, D.M. (1999). What is postmodern organization science?

http://www.business.nmsu.edu/ dbojepostmodscience.html. [27-032007]
Capra, F. (1982). Turning point, London: Flamingo.

Carnot. M. J., Dunn. B., Cañas A.J., Gram. P., Muldoon J.. (tt.) Institute for Human and Machine Cognition. Concept Maps vs. Web Pages for Information Searching and Browsing. Fhtt://www.pihmc.us/usersacanas/ PublicationsCMapsVSWebPagesExp 1CMapsVSWebPagesExp1.ht)

Herron (1977). Science Education. Problems Associated with Concept Analysis. Vol. 61. No. 2. pp: 185-199.

Landow, (1992). The Definition of Hypertext and Its History as a Concept. http://www.cyberartsweb.org/cpace/ht/ jhup/history.html\#1

Maswinara, I W. 1999. Sistem Filsafat Hindu (Sarva Darsana Samgraha). Surabaya: Penerbit Permata

Pendit, N. S. 2007. Filsafat Hindu Dharma Sad-Darsana Enam Aliran Astika (ortodoks), Buku Kedua. Denpasar: Pustaka Bali Post.

Plotnick, (1977). ERIC Clearinghouse on Information and Technology Syracuse NY. Concept Mapping: A Graphical System for Understanding the Relationship between Concepts. http://www.ericdigests.org/19981/concept.htm [25-03-2009]

Rutherford, F. J. \& Ahlgren, A. (1990). Scienk dipce for All Americans. New York: Oxford University Press.

Suja, I W. Retug. I.N. dan Siregar, M, Pengembangan Model Pembelajaran Kimia Berbasis Siklus Belajar Catur Praman. Laporan Penelitian: tidak dipublikasikan

Suja, I W., Sudria, I.B.N. \& Muderawan, I W. (2007). Integrasi Sains Asli (Indigeneus Science) ke dalam Kurikulum Sains Sekolah Sebagai Upaya Pengembangan Pendidikan Sains Berbasis Isi dan Context Budaya Bali. Laporan Peneltian (tidak diterbitkan). Singaraja: Universitas Pendidikan Ganesha.

Sumawa, I W. \& Krisnu, C. R. (1996). Materi Pokok Darsana. Jakarta: Direktorat 
Jendral Bimbingan Masyarakat Hindu dan Budha.

Suriasumantri, J. S. (2005). Filsafat IImu Sebuah Pengantar Populer. Jakarta: Pustaka Sinar harapan.

Team SMK-TI, (tt.). Overview Web. http://www.tutorial.smkn6dki.or.id/ modul.php

Tim Pemda Tingkat I Bali. 1999. Siwatattwa. Denpasar: Proyek Peningkatan Srana dan Prasarana Kehidupan Beragama Tersebar di sembilan Daerah Tingkat II 